\title{
The Important Factors Associated with Treatment Response in Laser Treatment of Facial Scars: A Single-Institution Based Retrospective Study
}

\author{
Youngkyoung Lim ${ }^{1}$, Ji-Hye Park ${ }^{1}$, Dong-Youn Lee ${ }^{1}, \mathrm{Na}$-Young Hwang ${ }^{2}$, Soohyun Ahn ${ }^{3}$, \\ Jong Hee Lee ${ }^{1,4}$ \\ ${ }^{1}$ Department of Dermatology, Samsung Medical Center, Sungkyunkwan University School of Medicine, ${ }^{2}$ Statistics and Data Center, \\ Samsung Medical Center, Seoul, ${ }^{3}$ Department of Mathematics, Ajou University, Suwon, ${ }^{4}$ Department of Medical Device Management $\mathcal{E}$ \\ Research, SAIHST, Sungkyunkwan University, Seoul, Korea
}

Background: There is increased interest in laser treatment of facial scars. Objective: To determine the factors associated with treatment response. Methods: We conducted an institution-based retrospective study by including the patients treated with laser for facial scars from 2012 to 2015. Treatment methods were determined with an algorithm according to individual scar characteristics. In each treatment session, either a 595-nm pulsed-dye laser or a non-ablative fractional laser was used, often in combination with a corticosteroid injection. We evaluated treatment responses based on the number of treatment sessions required to reach the treatment endpoint. Data were analyzed using multinomial logistic regression analysis to examine the association between treatment response and various factors of the scar. Results: A total of eighty-four scars were analyzed. The onset of treatment (defined as the period between the injury and treatment initiation), used laser modality, and the location of the scar were all found to be significantly associated with treatment responses. Early implementation was more

Received January 31, 2018, Revised June 27, 2018, Accepted for publication July 24, 2018

Corresponding author: Jong Hee Lee, Department of Dermatology, Samsung Medical Center, Sungkyunkwan University School of Medicine, 81 Irwon-ro, Gangnam-gu, Seoul 06351, Korea. Tel: 82-2-3410-3549, Fax: 82-2-3410-3869, E-mail: bell711@hanmail.net

ORCID: https://orcid.org/0000-0001-8536-1179

This is an Open Access article distributed under the terms of the Creative Commons Attribution Non-Commercial License (http://creativecommons. org/licenses/by-nc/4.0) which permits unrestricted non-commercial use, distribution, and reproduction in any medium, provided the original work is properly cited.

Copyright (c) The Korean Dermatological Association and The Korean Society for Investigative Dermatology likely to provide better treatment response. Scars on the perioral area were more likely to be associated with worse treatment response. Conclusion: The important factors for the treatment response in facial scars were the location of the scar and the timing of the initiation of treatment. Such information can be used to predict treatment response and tailor the treatment plan to the patient, depending on scar characteristics. (Ann Dermatol 31(1) 6 13, 2019)

\section{-Keywords-}

Face, Laser, Location, Scar

\section{INTRODUCTION}

Scarring is an inevitable result of the wound healing process ${ }^{1}$. Although scars are not representative of malignant lesions, they can have significant physical and emotional impacts on human life ${ }^{2-5}$. Scarring can occur on any parts of the body, but facial scars can seriously impair a patient's quality of life ${ }^{5}$. Therefore, there has been a growing interest in preventing and minimizing facial scars in recent years. Various methods such as the use of silicone agents, intralesional steroid injection, 5-fluorouracil, laser therapy, radiation therapy, cryotherapy, bleomycin, and pressure therapy have been proposed $^{6,7}$. In recent decades, laser therapy has been recognized as one of the most effective treatment methods for scars and many studies have provided evidence for its benefit ${ }^{6,8-10}$. Different types of lasers such as pulsed-dye laser (PDL), non-ablative fractional laser (NAFL), and ablative fractional laser (AFL) have been used for different types of scars ${ }^{1,4,10-13}$. 
Various factors, including patient characteristics and treatment-related factors, such as optimal treatment time and treatment modalities, can influence treatment outcomes. However, standardized guidelines for facial scar treatment have yet to be established. This study was designed to evaluate the factors that may play an important role in scar treatment and offer an optimal guideline for facial scar treatment.

\section{MATERIALS AND METHODS}

\section{Patients}

We reviewed the clinical data of all the patients treated with laser therapy for facial scarring at the Dermatology Clinic of Samsung Medical Center (SMC) from March 2012 to April 2015. This study was performed by reviewing electronic medical records and clinical photographs of all the patients. The study was approved by the SMC Institutional Review Board (IRB File No. 2016-11-122).

A total of 245 facial scars of patients who did not have a previous keloid history were treated with lasers during the study period. If the time of wound occurrence was unknown, or the Vancouver scar scale (VSS) of each scar was not recorded before and after treatment, the scars were excluded (38 scars) from the investigation. Patients who stopped receiving treatments before reaching their endpoint, or those who did not return within three months of their last treatment were excluded from this study (81 scars). Therefore, all the included scars in this study had reached the treatment endpoint. We also excluded cases in which laser treatment sessions were added for other purposes (e.g., melasma treatment, removal of nevus or wart, etc.) during scar treatment (16 scars). Due to an outbreak of Middle East Respiratory Syndrome, the out-patient clinic in our center was closed for three months (from June to August) in 2015 and the treatment duration for 26 scars was extended; these scars were also excluded from this study. All patients included in this study were Asians with Fitzpatrick skin types III IV.

\section{Treatment}

All the treatment sessions were conducted by a single laser expert. The optimal laser modality was selected according to the state of individual scars and selection was automated with a treatment algorithm (Fig. 1). In one treatment session, either a 595-nm PDL (V-Beam; Candela Laser Corporation, Wayland, MA, USA) or an NAFL (Fraxel Re:Store DUAL; Solta Medical, Hayward, CA, USA) was used. We used the PDL with a fluence between $7 \sim 9 \mathrm{~J} / \mathrm{cm}^{2}$ with a 7-mm spot size and a pulse width of 1.5 milliseconds. The NAFL was set to a $15 \sim 25 \mathrm{~mJ}$ energy

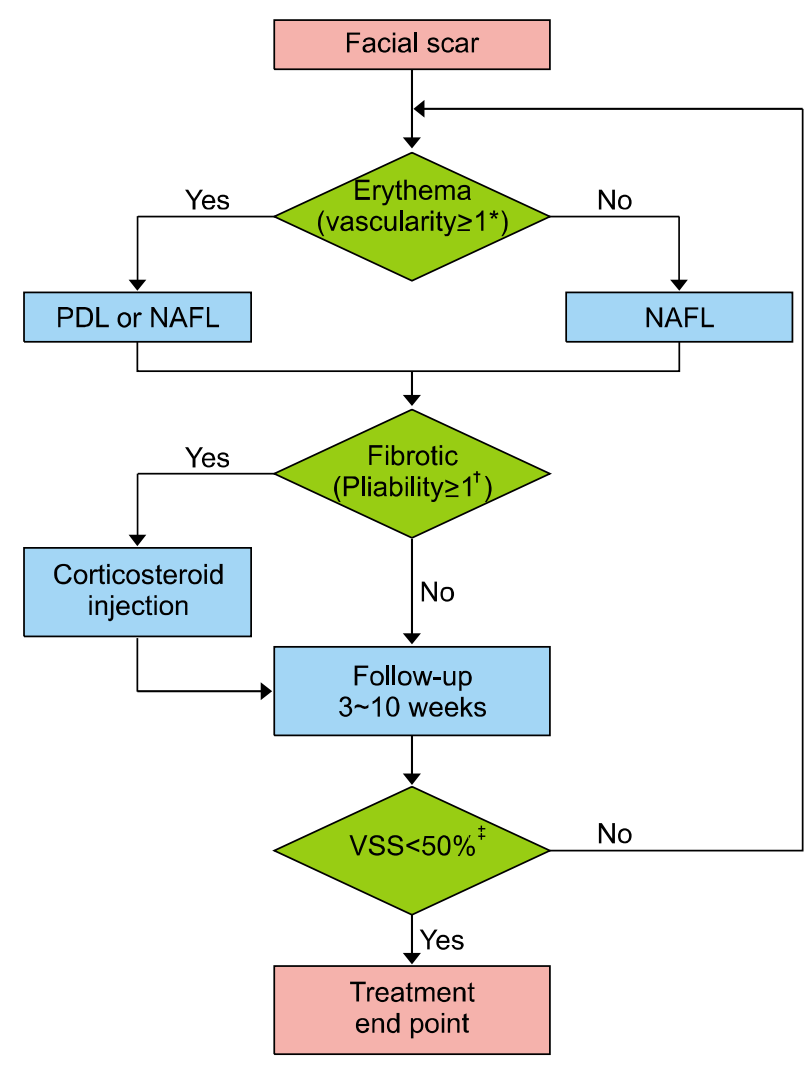

Fig. 1. The treatment algorithm: In one treatment session, either a 595-nm pulsed-dye laser (PDL) or a non-ablative fractional laser (NAFL) was used. Additionally, intralesional corticosteroid injection was employed in case of patients with pliability score $\geq 1$. Patients were asked to return between 3 and 10 weeks subsequent to treatment to check the status of their scar and determine whether continuing treatment was needed or whether the scar reached its treatment endpoint. *Vascularity (normal $=0$, pink $=1$, red $=2$, purple $=3$ ); ${ }^{\dagger}$ Pliability (normal $=0$, supple $=1$, yielding $=2$, firm $=3$, banding $=4$, contracture $=5$ ); ${ }^{\ddagger}$ The time point at which Vancouver scar scale (VSS) score was reduced by $50 \%$ was considered as the treatment endpoint.

level with treatment level 8 and $4 \sim 8$ passes. An intralesional corticosteroid injection $(2.5 \sim 5.0 \mathrm{mg} / \mathrm{ml}$ of triamcinolone acetonide [TA]) was combined with the laser treatment in cases with a pliability score of 1 or greater. Not more than $0.1 \sim 0.5 \mathrm{ml}$ of TA was injected per treatment session and was always used in conjunction with laser treatment. After the laser treatment, a cooling hydrogel was applied to all the patients for eight hours to calm down the treated sites, thus minimizing the risk of occurrence of possible adverse events after treatment. Patients were instructed to use topical moisturizer three times a day for a week after the treatment and afterward twice a day until their next visit. They were also asked to avoid sun exposure and use a broad-spectrum sunscreen. Patients were asked to follow-up between 3 and 10 weeks 
to check the status of their scar and to determine whether the treatment needed to be continued or if the scar had reached its treatment endpoint.

\section{End point and measurement}

Scars were sub-classified as flat, atrophic, hypertrophic, or adhesive prior to treatment. Flat scars were defined as scars without textural irregularity compared with adjacent normal skin. Adhesive scars were defined as any scars (flat, atrophic or hypertrophic) with contractures to the skin underneath it. The treatment effect was evaluated by two independent dermatologists using the $\mathrm{VSS}^{14}$. Each subcategory of the VSS, including vascularity (normal $=0$, pink $=1$, red $=2$, purple $=3$ ), pigmentation (normal =0, hypopigmentation $=1$, hyperpigmentation $=2$ ), pliability (normal $=0$, supple $=1$, yielding $=2$, firm $=3$, banding $=4$, contracture $=5$ ), and height (normal $=0,<2 \mathrm{~mm}=1,2 \sim 5 \mathrm{~mm}=$ $2,>5 \mathrm{~mm}=3$ ) was measured prior to each treatment session and at every follow up visit. For atrophic or adhesive scars, the depth of the scar region, when compared with the surrounding tissue, was considered to be the height. The time point at which a VSS reduction of $50 \%$ was observed was considered to be the treatment endpoint, which allowed for easier and more objective comparison. The number of treatment sessions required to reach the treatment endpoint (NTSE) was evaluated. Treatment response was considered to be good when NTSE was 1 or 2, moderate when NTSE was 3 or 4 , poor when NTSE was 5 or 6 , and resistant when NTSE was 7 or higher.

\section{Statistical analysis}

Previous studies have suggested that the onset of treatment (OT), defined as the period between the injury and treatment initiation, is associated with scar prognosis ${ }^{5,15,16}$. We thought that OT might be one of the important factors in determining the treatment response. Therefore, we divided scars into three groups according to OT and investigated the presence of significant differences in other variables. Simple descriptive statistics were used to describe the overall study population by OT groups. Fisher's exact test was used to compare the groups. The variables showing a significant difference in the comparison of OT groups were considered to be potential confounding variables. Next, considering the nature of the repeated measures and the fact that the treatment response is ordinal variable, generalized estimating equations for cumulative multinomial logistic regression analysis were performed. Further, a multivariable analysis was performed, considering the variables that were significant in the univariable analysis and the potential confounders from the comparison of the OT groups. Bonferroni cor- rected $p$-values were calculated. All statistical analyses were performed using $\mathrm{R}$ version 3.3.0 ( $\mathrm{R}$ Development Core Team, 2016). Statistical significance was set at $p<$ 0.05 .

\section{RESULTS}

Eighty-four scars of 64 patients were analyzed in this study. Most of the patients had a single facial scar $(n=48)$, and 16 patients had two or more scars. Overall, the median NTSE was 4 (range $1 \sim 10$ ) sessions. The median interval between treatment sessions was 6 (range $3 \sim 10$ ) weeks. The median treatment duration was 18.5 (range $3 \sim$ 65) weeks. The median initial VSS score was 5 (range $1 \sim$ 9 ), which reduced to 2 (range $0 \sim 4$ ) at the treatment endpoint.

When scars were grouped by OT $(\mathrm{m})$, the $\mathrm{m}<1,1 \leq \mathrm{m}<6$, and $m \geq 6$ groups differed significantly from each other based on several other factors (Table 1 ). When the laser treatment started earlier, more scars were observed in the better treatment response group, but differences between the OT groups were not statistically significant $(p=$ 0.0590). Scars of the $m<1$ group were more likely to be located on the forehead, while scars of the $m>6$ group were more likely to be located on the cheeks $(p=0.030)$. Flat scars were the most frequently occurring among the four scar types in the $\mathrm{m}<1$ group $(63.6 \%)$; however, hypertrophic scars were more frequent in the $1 \leq \mathrm{m}<6$ $(43.8 \%)$ and $m \geq 6(41.3 \%)$ groups $(p<0.001)$.

In univariable analyses, age, OT, and laser modalities (LM) were significantly associated with treatment response (Table 2). Subsequently, a multivariable analysis was performed considering the variables which were statistically significant in the univariable analysis and the potential confounders from the comparison of the OT groups. As a result, only three factors were found to be significantly associated with treatment response; OT, LM, and the location of the scar. Among the OT groups, there was a significant difference in the treatment response of the scar treated earlier within a month and the scar treated after 6 months $(p=0.0035)$. Considering scar locations, particularly, scars on the perioral area and scars on the periocular area showed a significant difference in treatment response $(p=0.0324)$. The group of patients who were treated using both PDL and NAFL showed a significantly worse treatment response when compared to the group of patients treated using only PDL $(p=0.0011)$.

\section{DISCUSSION}

This study was designed to identify the valuable factors for 
Table 1. Different characteristics of facial scars according to treatment onset

\begin{tabular}{|c|c|c|c|c|}
\hline \multirow{2}{*}{ Factors } & \multicolumn{3}{|c|}{ Onset of $\mathrm{Tx}^{*}$} & \multirow{2}{*}{$p$-value } \\
\hline & $\mathrm{m}<1$ & $1 \leq \mathrm{m}<6$ & $6 \leq \mathrm{m}$ & \\
\hline \multicolumn{5}{|l|}{ Sex } \\
\hline Female & $10(45.5)$ & $13(81.2)$ & $26(56.5)$ & \multirow[t]{2}{*}{0.076} \\
\hline Male & $12(54.5)$ & $3(18.8)$ & $20(43.5)$ & \\
\hline \multicolumn{5}{|l|}{ Age $(y)$} \\
\hline$y<10$ & 9 (40.9) & $3(18.8)$ & $0(0.0)$ & \multirow[t]{6}{*}{$<0.001^{\ddagger}$} \\
\hline $10 \leq y<20$ & $2(9.1)$ & $0(0.0)$ & $13(28.3)$ & \\
\hline $20 \leq y<30$ & $6(27.3)$ & $4(25.0)$ & $14(30.4)$ & \\
\hline $30 \leq y<40$ & $1(4.5)$ & $0(0.0)$ & 11 (23.9) & \\
\hline $40 \leq y<50$ & $1(4.5)$ & $4(25.0)$ & $4(8.7)$ & \\
\hline $50 \leq y$ & 3 (13.6) & $5(31.2)$ & $4(8.7)$ & \\
\hline \multicolumn{5}{|l|}{ Location } \\
\hline Forehead & $7(31.8)$ & $5(31.2)$ & $7(15.2)$ & \multirow[t]{5}{*}{$0.030^{\ddagger}$} \\
\hline Nose & $4(18.2)$ & $3(18.8)$ & $4(8.7)$ & \\
\hline Perioral area & $2(9.1)$ & $4(25.0)$ & 7 (15.2) & \\
\hline Cheek & $4(18.2)$ & $2(12.5)$ & $24(52.2)$ & \\
\hline Periocular area & $5(22.7)$ & $2(12.5)$ & $4(8.7)$ & \\
\hline \multicolumn{5}{|l|}{ Cause } \\
\hline Trauma & 9 (40.9) & 7 (43.8) & $13(28.3)$ & \multirow[t]{4}{*}{0.338} \\
\hline Operation & $13(59.1)$ & 7 (43.8) & $24(52.2)$ & \\
\hline Burn & $0(0.0)$ & $0(0.0)$ & $4(8.7)$ & \\
\hline Others & $0(0.0)$ & $2(12.5)$ & $5(10.9)$ & \\
\hline \multicolumn{5}{|l|}{ Type } \\
\hline Flat & 14 (63.6) & $1(6.2)$ & $4(8.7)$ & \multirow[t]{4}{*}{$<0.001^{\ddagger}$} \\
\hline Atrophic & $0(0.0)$ & $2(12.5)$ & 11 (23.9) & \\
\hline Hypertrophic & $6(27.3)$ & 7 (43.8) & 19 (41.3) & \\
\hline Adhesive & $2(9.1)$ & $6(37.5)$ & $12(26.1)$ & \\
\hline \multicolumn{5}{|l|}{ Initial VSS } \\
\hline$<5$ & $13(59.1)$ & $5(31.2)$ & $22(47.8)$ & \multirow[t]{2}{*}{0.268} \\
\hline$\geq 5$ & $9(40.9)$ & $11(68.8)$ & $24(52.2)$ & \\
\hline \multicolumn{5}{|l|}{ Laser modality $^{\dagger}$} \\
\hline PDL only & $2(9.1)$ & $0(0.0)$ & $3(6.5)$ & \multirow[t]{3}{*}{0.296} \\
\hline NAFL only & $10(45.5)$ & $9(56.2)$ & $31(67.4)$ & \\
\hline PDL and NAFL both & $10(45.5)$ & $7(43.8)$ & $12(26.1)$ & \\
\hline \multicolumn{5}{|l|}{ Corticosteroid injection } \\
\hline No & 14 (63.6) & $11(68.8)$ & 34 (73.9) & \multirow[t]{2}{*}{0.691} \\
\hline Yes & $8(34.4)$ & $5(31.2)$ & $12(26.1)$ & \\
\hline \multicolumn{5}{|l|}{ Tx response } \\
\hline Good & $11(50.0)$ & $6(37.5)$ & 9 (19.6) & \multirow[t]{4}{*}{0.059} \\
\hline Moderate & $8(36.4)$ & $5(31.2)$ & $18(39.1)$ & \\
\hline Poor & $3(13.6)$ & $2(12.5)$ & 15 (32.6) & \\
\hline Resistant & $0(0.0)$ & $3(18.8)$ & $4(8.7)$ & \\
\hline
\end{tabular}

Values are presented as number (\%). Percentages may not add up to 100 due to rounding. Tx: treatment, $\mathrm{m}$ : months, y: years, VSS: Vancouver scar scale, PDL: $595-\mathrm{nm}$ pulsed-dye laser, NAFL: non-ablative fractional laser. ${ }^{*}$ The period between the injury and initiation of laser treatment. ${ }^{\dagger}$ Used laser modalities were selected via an algorithm according to the state of individual scars. ${ }^{\dagger} p<0.05$.

predicting treatment response of laser treatment for facial scars. With the help of biostatistics specialists, we analyzed possible influencing factors based on their treatment response, for which we determined values by the NTSE. NTSE was defined as the number of treatments needed to achieve a VSS decrease of $\geq 50 \%$, compared with the ini- tial score. Therefore, the smaller NTSE values indicated the better treatment response and the larger NTSE values vice versa.

Among many treatment modalities, lasers have been successfully used for scar treatment, and among them, 585-nm or 595-nm PDL and NAFL have been consistently 
Table 2. Univariable and multivariable analyses of the effects of various factors on treatment response

\begin{tabular}{|c|c|c|c|c|c|c|}
\hline \multirow[b]{2}{*}{ Factors } & \multicolumn{4}{|c|}{ Tx response $(n=84)$} & \multirow{2}{*}{$\frac{\text { Univariableanalysis }}{p \text {-value }}$} & \multirow{2}{*}{$\frac{\text { Multivariableanalysis }}{p \text {-value }}$} \\
\hline & $\begin{array}{c}\text { Good } \\
(n=26)\end{array}$ & $\begin{array}{c}\text { Moderate } \\
(\mathrm{n}=31)\end{array}$ & $\begin{array}{c}\text { Poor } \\
(n=20)\end{array}$ & $\begin{array}{l}\text { Resistant } \\
(\mathrm{n}=7)\end{array}$ & & \\
\hline \multicolumn{7}{|l|}{ Sex } \\
\hline Female & $13(26.5)$ & $20(40.8)$ & $12(24.5)$ & $4(8.2)$ & Ref. & - \\
\hline Male & $13(37.1)$ & $11(31.4)$ & $8(22.9)$ & $3(8.6)$ & 0.4192 & \\
\hline \multicolumn{7}{|l|}{ Age $(y)$} \\
\hline$y<10$ & $7(58.3)$ & $5(41.7)$ & $0(0.0)$ & $0(0.0)$ & Ref. & Ref. \\
\hline $10 \leq y<20$ & $3(20.0)$ & $2(13.3)$ & $8(53.3)$ & $2(13.3)$ & 0.0555 & 0.5306 \\
\hline $20 \leq y<30$ & $9(37.5)$ & $8(33.3)$ & $7(29.2)$ & $0(0.0)$ & 0.4719 & 0.7868 \\
\hline $30 \leq y<40$ & $2(16.7)$ & $8(66.7)$ & $0(0.0)$ & $2(16.7)$ & $0.0135^{\ddagger}$ & 0.2289 \\
\hline $40 \leq y<50$ & $1(11.1)$ & $4(44.4)$ & $2(22.2)$ & $2(22.2)$ & 0.1647 & 0.0908 \\
\hline $50 \leq y$ & $4(33.3)$ & $4(33.3)$ & $3(25.0)$ & $1(8.3)$ & 0.6548 & 0.2560 \\
\hline \multicolumn{7}{|l|}{ Location } \\
\hline Forehead & $5(26.3)$ & $9(47.4)$ & $5(26.3)$ & $0(0.0)$ & 1 & 0.9783 \\
\hline Nose & $4(36.4)$ & $4(36.4)$ & $2(18.2)$ & $1(9.1)$ & 0.0960 & 0.7947 \\
\hline Perioral area & $2(15.4)$ & $2(15.4)$ & $6(46.2)$ & $3(23.1)$ & Ref. & Ref. \\
\hline Cheek & $8(26.7)$ & $13(43.3)$ & $7(23.3)$ & $2(6.7)$ & 0.9076 & 0.3087 \\
\hline Periocular area & $7(63.6)$ & $3(27.3)$ & $0(0.0)$ & $1(9.1)$ & 0.1707 & $0.0324^{\ddagger}$ \\
\hline \multicolumn{7}{|l|}{ Cause } \\
\hline Trauma & $12(41.4)$ & 8 (27.6) & $8(27.6)$ & $1(3.4)$ & 0.9636 & - \\
\hline Operation & 14 (31.8) & $18(40.9)$ & 7 (15.9) & $5(11.4)$ & Ref. & \\
\hline Burn & $0(0.0)$ & $1(25.0)$ & $3(75.0)$ & $0(0.0)$ & 0.2085 & \\
\hline Others & $0(0.0)$ & $4(57.1)$ & $2(28.6)$ & 1 (14.3) & 0.3210 & \\
\hline \multicolumn{7}{|l|}{ Type } \\
\hline Flat & $9(47.4)$ & $8(42.1)$ & $0(0.0)$ & $2(10.5)$ & 0.1281 & 0.8692 \\
\hline Atrophic & $3(23.1)$ & $5(38.5)$ & $5(38.5)$ & $0(0.0)$ & 1 & 0.9336 \\
\hline Hypertrophic & $6(18.8)$ & $9(28.1)$ & $13(40.6)$ & $4(12.5)$ & Ref. & Ref. \\
\hline Adhesive & $8(40.0)$ & $9(45.0)$ & $2(10.0)$ & $1(5.0)$ & 1 & 0.4550 \\
\hline \multicolumn{7}{|l|}{ Onset of $T x(m)^{*}$} \\
\hline $\mathrm{m}<1$ & $11(50.0)$ & $8(36.4)$ & 3 (13.6) & $0(0.0)$ & Ref. & Ref. \\
\hline $1 \leq \mathrm{m}<6$ & $6(37.5)$ & $5(31.3)$ & $2(12.5)$ & $3(18.8)$ & 0.6243 & 0.3576 \\
\hline $6 \leq \mathrm{m}$ & 9 (19.6) & $18(39.1)$ & 15 (32.6) & $4(8.7)$ & $0.0028^{\ddagger}$ & $0.0035^{\ddagger}$ \\
\hline \multicolumn{7}{|l|}{ Initial VSS } \\
\hline$<5$ & $17(42.5)$ & $11(27.5)$ & $9(22.5)$ & $3(7.5)$ & Ref. & - \\
\hline$\geq 5$ & 9 (20.5) & $20(45.5)$ & $11(25.0)$ & $4(9.1)$ & 0.1479 & \\
\hline \multicolumn{7}{|l|}{ Laser modality $^{\dagger}$} \\
\hline PDL only & $3(60.0)$ & $2(40.0)$ & $0(0.0)$ & $0(0.0)$ & Ref. & Ref. \\
\hline NAFL only & $22(44.0)$ & 18 (36.0) & $9(18.0)$ & $1(2.0)$ & 0.5576 & 0.1439 \\
\hline PDL, NAFL both & $1(3.4)$ & $11(37.9)$ & $11(37.9)$ & $6(20.7)$ & $0.0176^{\ddagger}$ & $0.0011^{\ddagger}$ \\
\hline \multicolumn{7}{|l|}{ Corticosteroidinjection } \\
\hline No & $22(100.0)$ & $0(0.0)$ & $0(0.0)$ & $0(0.0)$ & Ref. & - \\
\hline Yes & $4(6.5)$ & $31(50.0)$ & $20(32.3)$ & $7(11.3)$ & 0.3618 & \\
\hline
\end{tabular}

Values are presented as number (\%). Percentages may not add up to 100 due to rounding. Tx: treatment, $y:$ years, m: months, VSS: Vancouver scar scale, PDL: 595-nm pulsed-dye laser, NAFL: non-ablative fractional laser, Ref.: reference. *The period between the injury and initiation of laser treatment. ${ }^{\dagger}$ Used laser modalities were selected via an algorithm according to the state of individual scars. ${ }^{\ddagger} p<0.05$.

reported to be effective and safe $e^{1,7,11,17,18}$. In this study, scars were treated with one of these two lasers based on a treatment algorithm. Corticosteroid injection (CSI) is the most popularly used treatment modality for scarring ${ }^{19,20}$. However, for facial scars, cosmetic concerns are a priority and, therefore, possible adverse effects such as steroid-induced atrophy or CSI-related telangiectasia are not often acceptable to patients. For this reason, we limited the use of CSI to the lowest concentration possible and used it only for scars with high pliability scores. 
In the present study, scars showed a tendency of having better treatment response, when laser treatment was initiated earlier following injury. The optimal timing for initiating laser scar treatment has not yet been determined. Traditionally, laser treatments are started after the wound had matured, which meant several months after trauma or surgery $^{11,15}$. Some researchers have reported that laser treatment could be effectively started $2 \sim 3$ months after scar stabilization and when erythema had decreased at the surgical site ${ }^{21}$. However, earlier interventions have been emphasized in recent years to prevent hypertrophic scar formation ${ }^{15}$. Studies have shown that earlier interventions using PDL could be started without waiting for the wound to mature ${ }^{18}$. It has also been reported that early treatment with fractional lasers, such as AFL or NAFL, is beneficial $^{15,16,22-24}$.

In general, the progression of a wound healing process comprises of the following phases; the inflammation phase for a few days, the proliferation phase for weeks, and the maturation phase for several months or years. Previous studies have shown that hypertrophic scars generally begin to develop 6 to 8 weeks after wound healing, grow rapidly for $3 \sim 6$ months, and then gradually regress after 6 months ${ }^{25,26}$. Lasers generate heat to cause inflammation and increase the permeability of blood vessels, matrix metalloproteinase production, and degradation of collagen fibers ${ }^{17,18}$. Moreover, targeted blood-vessel destruction induces hypoxia in the tissue, thereby reducing fibroblast proliferation and interfering with collagen deposition ${ }^{17,18}$. Thus, early implementation of laser treatment can shorten the acute inflammation stage, accelerate scar maturation, and prevent excessive scar formation ${ }^{17}$. Consistently, the results of the current study suggested that early active intervention of scars may reduce the number of treatments and show better treatment response rather than the conventional wait-and-see or delayed scar treatment until the natural course of scar maturation.

Interestingly, our results showed that the location of the scar was also significantly related to treatment outcome and especially scars on the perioral area had worse treatment response than scars on other areas. Particular areas of the body are more likely to develop hypertrophic scars, especially the front chest, shoulder, and the lower abdomen ${ }^{7,27}$. This might be due to different degrees of mechanical tension at each region ${ }^{7,28}$. The perioral area is also an example of a highly movable area that is associated with larger mechanical tension due to the attachment of masticatory or facial muscles. Therefore, scars occurring on the perioral area are expected to respond poorly to the treatment.
The superiority of certain laser modality over others in scar treatment has not been reported until now ${ }^{9,16,17}$. However, the present study showed the statistically significant association of LM with treatment response in the multivariable analysis, which could be due to the nature of our treatment algorithm in which only one type of laser can be used in a single treatment session. To be precise, if both PDL and NAFL had been used on a scar, it was evident that the scar must have been treated at least twice. However, in the PDL only group or the NAFL only group, patients treated with only one session of each laser treatment is included. Therefore, among the three groups of LM, in the group using both PDL and NAFL, NTSE could inevitably be predicted to be higher than the groups using only one modality among PDL and NAFL.

This study has a few limitations. First, because this study was the retrospective analysis of patients, comparative analysis with the untreated control groups was not carried out. Second, incomplete clinical data and follow-up loss limited the number of scars that we could include in the analyses. Third, the exclusion criteria eliminating the patients who had stopped receiving treatments before reaching the endpoint of treatment might obtain biased results with better treatment response. Fourth, the use of different detailed treatment methods, depending on individual scar characteristics, was a serious analysis concern. However, all the scars were treated by one laser specialist following the same algorithm, and LM was controlled in our multivariable analysis. Lastly, the study population was limited to Asian patients with Fitzpatrick skin type III or IV.

Despite these limitations, the discovery that OT is associated with treatment response is of major clinical significance. In the daily practice, patients with facial scars often prefer to get treated as soon as possible and to the maximum extent possible and do not wish to wait for the natural course of scar maturation. Our results provide indirect evidence to the argument that early active laser intervention for scars yields better and faster outcomes compared to the conventional wait-and-see scar treatment that recommends delayed treatment until scar maturation.

Although we investigated the effects of several factors on the scar-treatment response, other factors may also affect the outcomes of scar treatment. In addition to the factors analyzed in the present study, anemia, ischemia, hormones, stress, smoking, alcohol consumption, obesity and body mass index, medications, and underlying conditions (immunocompromised, diabetes, malnutrition, etc.) are known to influence wound healing ${ }^{18,29,30}$. Therefore, in future studies, the above-mentioned factors should be considered.

In conclusion, the most important factors associated with 
the treatment response in facial scars were the location of the scar and the timing of the start of treatment. The latter seemed to be the only modifiable factor for patients to achieve better treatment response among the factors we analyzed. Therefore, physicians should advise patients with a facial scar that early active intervention may help them in reducing the number of treatment sessions required, save cost and time, and achieve more desirable clinical outcomes. In addition, our results revealed that scars on different locations may show a different response to the treatment. Especially, patients with scars on the perioral area might require more treatment sessions. Such information can be used to predict treatment response and to tailor the treatment plan, depending on the characteristics of the scar. To ensure the generalizability of these results, further research is required involving larger populations at multiple centers over a longer period of time.

\section{CONFLICTS OF INTEREST}

The authors have nothing to disclose.

\section{ORCID}

Youngkyoung Lim, https://orcid.org/0000-0002-6409-2704

Ji-Hye Park, https://orcid.org/0000-0002-6699-5202

Dong-Youn Lee, https://orcid.org/0000-0003-0765-9812

Na-Young Hwang, https://orcid.org/0000-0001-6282-5946

Soohyun Ahn, https://orcid.org/0000-0001-5016-5469

Jong Hee Lee, https://orcid.org/0000-0001-8536-1179

\section{REFERENCES}

1. Balaraman B, Geddes ER, Friedman PM. Best reconstructive techniques: improving the final scar. Dermatol Surg 2015; 41 Suppl 10:S265-S275.

2. Bock O, Schmid-Ott G, Malewski P, Mrowietz U. Quality of life of patients with keloid and hypertrophic scarring. Arch Dermatol Res 2006;297:433-438.

3. Lawrence JW, Mason ST, Schomer K, Klein MB. Epidemiology and impact of scarring after burn injury: a systematic review of the literature. J Burn Care Res 2012;33:136-146.

4. van Drooge AM, Vrijman C, van der Veen W, Wolkerstorfer A. A randomized controlled pilot study on ablative fractional $\mathrm{CO} 2$ laser for consecutive patients presenting with various scar types. Dermatol Surg 2015;41:371-377.

5. Parry I, Sen S, Palmieri T, Greenhalgh D. Nonsurgical scar management of the face: does early versus late intervention affect outcome? J Burn Care Res 2013;34:569-575.

6. Gold MH, Berman B, Clementoni MT, Gauglitz GG, Nahai $\mathrm{F}$, Murcia C. Updated international clinical recommendations on scar management: part 1--evaluating the evidence. Dermatol Surg 2014;40:817-824.
7. Tziotzios C, Profyris C, Sterling J. Cutaneous scarring: pathophysiology, molecular mechanisms, and scar reduction therapeutics part II. Strategies to reduce scar formation after dermatologic procedures. J Am Acad Dermatol 2012;66:1324; quiz 25-26.

8. Haedersdal M, Moreau KE, Beyer DM, Nymann P, Alsbjørn B. Fractional nonablative $1540 \mathrm{~nm}$ laser resurfacing for thermal burn scars: a randomized controlled trial. Lasers Surg Med 2009;41:189-195.

9. Vasily DB, Cerino ME, Ziselman EM, Zeina ST. Non-ablative fractional resurfacing of surgical and post-traumatic scars. J Drugs Dermatol 2009;8:998-1005.

10. Cervelli V, Gentile P, Spallone D, Nicoli F, Verardi S, Petrocelli $M$, et al. Ultrapulsed fractional $\mathrm{CO} 2$ laser for the treatment of post-traumatic and pathological scars. J Drugs Dermatol 2010;9:1328-1331.

11. Anderson RR, Donelan MB, Hivnor C, Greeson E, Ross EV, Shumaker PR, et al. Laser treatment of traumatic scars with an emphasis on ablative fractional laser resurfacing: consensus report. JAMA Dermatol 2014;150:187-193.

12. Vrijman C, van Drooge AM, Limpens J, Bos JD, van der Veen JP, Spuls PI, et al. Laser and intense pulsed light therapy for the treatment of hypertrophic scars: a systematic review. Br J Dermatol 2011;165:934-942.

13. Verhaeghe E, Ongenae K, Bostoen J, Lambert J. Nonablative fractional laser resurfacing for the treatment of hypertrophic scars: a randomized controlled trial. Dermatol Surg 2013; 39:426-434.

14. Baryza MJ, Baryza GA. The Vancouver scar scale: an administration tool and its interrater reliability. J Burn Care Rehabil 1995; 16:535-538.

15. Park KY, Oh IY, Seo SJ, Kang KH, Park SJ. Appropriate timing for thyroidectomy scar treatment using a 1,550-nm fractional erbium-glass laser. Dermatol Surg 2013;39:18271834.

16. Jung JY, Jeong JJ, Roh HJ, Cho SH, Chung KY, Lee WJ, et al. Early postoperative treatment of thyroidectomy scars using a fractional carbon dioxide laser. Dermatol Surg 2011;37: 217-223.

17. Jin R, Huang X, Li H, Yuan Y, Li B, Cheng C, et al. Laser therapy for prevention and treatment of pathologic excessive scars. Plast Reconstr Surg 2013;132:1747-1758.

18. Cooper JS, Lee BT. Treatment of facial scarring: lasers, filler, and nonoperative techniques. Facial Plast Surg 2009;25: 311-315.

19. Atiyeh BS. Nonsurgical management of hypertrophic scars: evidence-based therapies, standard practices, and emerging methods. Aesthetic Plast Surg 2007;31:468-492; discussion 493-464.

20. Ledon JA, Savas J, Franca K, Chacon A, Nouri K. Intralesional treatment for keloids and hypertrophic scars: a review. Dermatol Surg 2013;39:1745-1757.

21. Kunishige $\mathrm{JH}$, Katz TM, Goldberg LH, Friedman PM. Fractional photothermolysis for the treatment of surgical scars. Dermatol Surg 2010;36:538-541.

22. Choe JH, Park YL, Kim BJ, Kim MN, Rho NK, Park BS, et al. Prevention of thyroidectomy scar using a new 1,550-nm 
fractional erbium-glass laser. Dermatol Surg 2009;35:11991205.

23. Kim HS, Lee JH, Park YM, Lee JY. Comparison of the effectiveness of nonablative fractional laser versus ablative fractional laser in thyroidectomy scar prevention: a pilot study. J Cosmet Laser Ther 2012;14:89-93.

24. Kim SG, Kim EY, Kim YJ, Lee SI. The efficacy and safety of ablative fractional resurfacing using a 2,940-Nm Er:YAG laser for traumatic scars in the early posttraumatic period. Arch Plast Surg 2012;39:232-237.

25. Gold MH, McGuire M, Mustoe TA, Pusic A, Sachdev M, Waibel J, et al. Updated international clinical recommendations on scar management: part 2--algorithms for scar prevention and treatment. Dermatol Surg 2014;40:825-831.

26. Chun Q, ZhiYong W, Fei S, XiQiao W. Dynamic biological changes in fibroblasts during hypertrophic scar formation and regression. Int Wound J 2016;13:257-262.

27. Agha R, Ogawa R, Pietramaggiori G, Orgill DP. A review of the role of mechanical forces in cutaneous wound healing. J Surg Res 2011;171:700-708.

28. On HR, Lee SH, Lee YS, Chang HS, Park C, Roh MR. Evaluating hypertrophic thyroidectomy scar outcomes after treatment with triamcinolone injections and copper bromide laser therapy. Lasers Surg Med 2015;47:479-484.

29. Guo S, Dipietro LA. Factors affecting wound healing. J Dent Res 2010;89:219-229.

30. Khalil H, Cullen $M$, Chambers $H$, Carroll $M$, Walker J. Elements affecting wound healing time: an evidence based analysis. Wound Repair Regen 2015;23:550-556. 